\title{
Autonomic control of cardiovascular reflexes in narcolepsy
}

\author{
CHARLOTTE SACHS AND LENNART KAIJSER
}

From the Departments of Neurology and Clinical Physiology, Karolinska sjukhuset, Stockholm

SUMMARY Six male patients with narcolepsy for several years, were studied without and with amphetamine in order to evaluate possible abnormalities in autonomic control of the cardiovascular system. Studies were made of (1) heart rate and blood flow in the resting forearm during contralateral isometric handgrip, (2) respiratory sinus arrhythmia and (3) heart rate response to the Valsalva manoeuvre. The patients had a slow heart rate, a reduced forearm blood flow increase on handgrip, and a subnormal sinus arrhythmia. Only two out of the six patients had an abnormal Valsalva ratio. Amphetamine did not alter the response to handgrip but increased the sinus arrhythmia in three patients and the Valsalva ratio in two. It is concluded that narcolepsy is accompanied by reduced vegetative reactivity in the cardiovascular system. Since this applies to functions mediated by both the sympathetic and parasympathetic systems, and since some parasympathetically-mediated functions are affected while others are not, the functional disturbance found probably is of central origin.

Narcolepsy is a clinical entity characterised by sleep attacks, cataplexy, sleep paralysis and hypnagogic hallucinations. Patients with narcolepsy also exhibit hippus, ie rhythmic constrictions and dilatations of the pupil independent of illumination. ${ }^{12}$ This phenomenon has been ascribed to a poor autonomic balance of unknown origin and is abolished by therapeutic doses of amphetamine.

In addition to EEG abnormalities, hippus is the only objective sign of neurophysiological dysfunction in narcolepsy. We therefore considered it of interest to see if some other vegetative disturbances were present. We have investigated some cardiovascular reflexes mediated by the vegetative nervous system: - (1) the heart rate response together with the blood flow response in the resting forearm to contralateral handgrip, ${ }^{3}{ }^{4}(2)$ the respiratory sinus arrhythmia ${ }^{5}$ and (3) the heart rate response to the Valsalva manoeuvre. ${ }^{6}$

\section{Patients}

Six male patients were studied with clinically well defined narcolepsy for several years, referred from the neurological outpatient clinic. Their mean age was 48 years (range 38-62 years). Four

Address for reprint requests: Dr Charlotte Sachs, Department of Neurology, Karolinska sjukhuset, S-104 01 Stockholm, Sweden.

Accepted 21 February 1980 of the patients had severe and two moderate symptoms (in the table and figures the patients are numbered according to the severity of the symptoms; 1 is the patient with the most severe symptoms). They had no history of sleep apnoea. All took amphetamine with good clinical effect for several years (The daily doses ranged from 10 to $30 \mathrm{mg}$ of d,1-amphetamine). They took no other medication. One of them (case 4) had had a previous myocardial infarction, the others had no history or signs of any other disease than narcolepsy.

The study was approved by the Ethical Committée of the Karolinska institute.

\section{Methods}

All measurements were performed in the morning after three days without amphetamine medication with the patient in the supine position. Measurements were done before and one hour after the usual morning dose of amphetamine, which ranged between 7.5 and $15 \mathrm{mg}$. Three sets of experiments were performed:

1 Contralateral isometric handgrip (CIH) Isometric handgrip at $1 / 3$ of maximal voluntary contraction force (MVC) was held for $2 \mathrm{~min}$ utilising a strain gauge dynamometer. The force developed was shown on an oscilloscope so as to make it possible for the patient to maintain the predetermined force. The individual MVC 
was measured before the experiment. Blood flow in the resting, contralateral arm was measured by venous occlusion plethysmography ${ }^{7}$ and recorded together with the heart rate on an ink jet recorder (Siemens Elema) before, during and after the contraction. ${ }^{3}$ In each patient the figures given are the mean of two contractions. For each contraction resting blood flow is the mean of six inflow curves. The flow curves during contracticn were taken at $15 \mathrm{~s}$ intervals.

2 Respiratory sinus arrhythm: $a$ (RSA) The patients breathed through a mouthpiece and pneumotachograph in pace with a triangular wave form from a signal generator shown on an oscilloscope which served to guide the patient to breathe at the rate of six breaths per min with i) tidal volume of 21 (Melcher 1976). RSA is defined as the difference between the highest and lowest heart rate during a respiratory cycle (calculated from the shortest and longest beat intervals), each figure given is the mean of ten consecutive cycles.

3 Valsalva rato The patients were instructed to maintain an expiratory pressure of $40 \mathrm{~mm}$ $\mathrm{Hg}$ for $20 \mathrm{~s}$ by blowing through a mouthpiece which permitted a slow airflow ("leak"). The pressure was measured by a mercury manometer shown to the patient. The leak prevented the patient from maintaining the pressure by his cheeks with closed glottis. The Valsalva ratio is defined as the ratio, between the highest heart rate during, and the lowest heart rate for the first $20 \mathrm{~s}$ after the expiration. ${ }^{6}$ The value for each subject is the mean of three Valsalva m?noeuvres.

The results were compared with those of healthy volunteers of the same sex and age, studied in the same laboratory (CIH, ${ }^{4}$ RSA. ${ }^{89}$ ) In addition the effect of amphetamine on CIH, RSA and Valsalva ratio in healthy subjects was studied in a separate group of healthy volunteers ( 3 males, 3 females age 28-42 years) who were selected so that subjects with the greatest and the smallest forearm blood flow increase on hand grip were included. They were studied before and $60 \mathrm{~min}$ after $10 \mathrm{mg}$ amphetamine by mouth.

Unless otherwise stated values in the text are mean \pm SD of the group.

\section{Results}

1 Contralateral isometric handgrip Basal heart rate was $63 \pm 11$ beats $/ \mathrm{min}$. On handgrip it increased to a maximal value of $75 \pm 11$ beats $/ \mathrm{min}$ after $2 \mathrm{~min}$. The increase was in all patients significantly smaller than in the control group

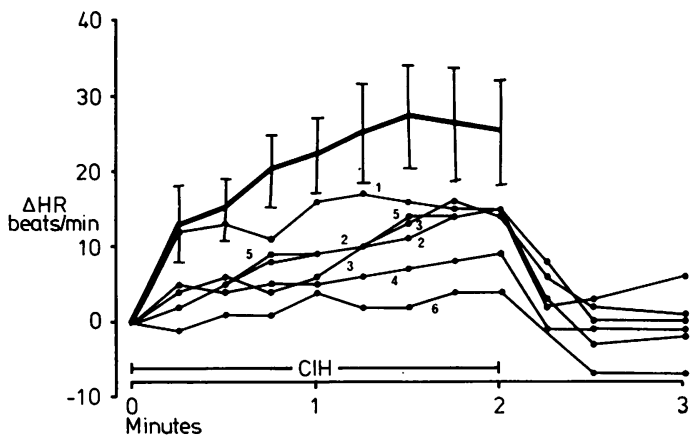

Fig 1 Heart rate change during and after isometric handgrip at $1 / 3 \mathrm{MVC}$ for $2 \mathrm{~min}$. Data from the intividual patients and mean $\pm S D$ of the control group. The patients are numbered according to clinical severity of the disease, 1 representing the patient with the most severe symptoms.

who had a resting heart rate of $63 \pm 8$ which increased to $92 \pm 9$ beats/min during handgrip (fig 1).

Resting heart rate after amphetamine was $68 \pm 11$ beats $/ \mathrm{min}$ which was not significantly different from that without the drug $(p>0.05)$. The heart rate increase during handgrip was the same as without amphetamine (fig 2).

Forearm blood flow was $29 \pm 9 \mathrm{ml} \mathrm{min}^{-1} \mathrm{1}^{-1}$, which was not significantly different from that in the control group, $36 \pm 12 \mathrm{ml} \mathrm{min}^{-1} \mathrm{l}^{-1}$. During handgrip it increased in all patients to an average maximal value of $44 \pm 15 \mathrm{ml} \mathrm{min}^{-1} \mathrm{1}^{-1}$, which was reached after $30-120 \mathrm{~s}$ in the different patients (fig 3,4$)$. The average increase for the group was significantly smaller and was achieved later than in the control group in which a maximal flow of $80 \pm 32 \mathrm{mil} \mathrm{min}^{-1} 1^{-1}$ was recorded, most often after about $60 \mathrm{~s}$.

Of the individual patients two showed an in-

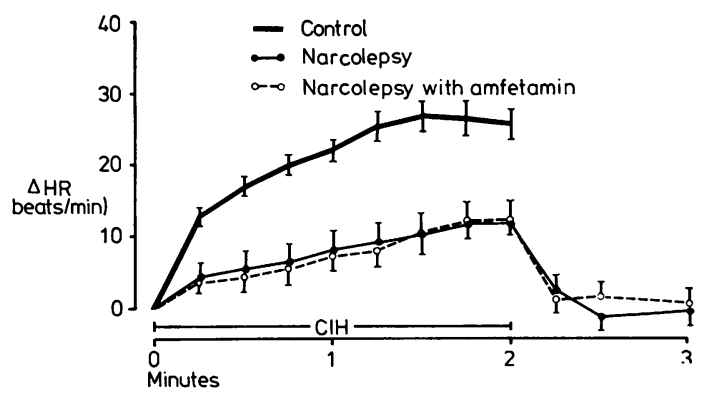

Fig 2 Heart rate change during and after isometric handgrip at 1/3 MVC for 2 min in the narcolepsy patients before and after amphetamine and in the control group. Mean $\pm S E$ for each category. 


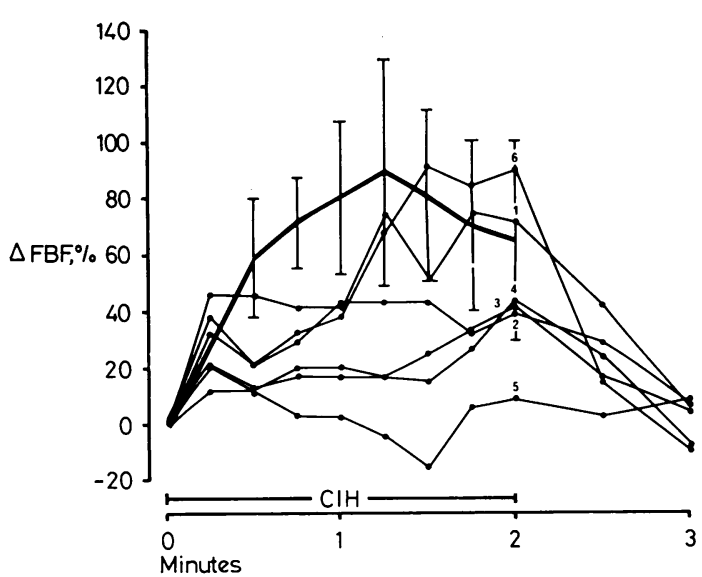

Fig 3 Change in blood flow in the resting forearm during and after contralateral isometric handgrip at 1/3 MVC for 2 min. Data from the individual patients and mean $\pm S D$ of the control group.

crease rather similar to that in the normal subjects, whereas four had significantly smaller increase (fig 3).

After amphetamine basal forearm blood flow was $29 \pm 17 \mathrm{ml} \mathrm{min}^{-1} \mathrm{1}^{-1}$ which was not significantly different from that without the drug. During handgrip the flow was the same as without amphetamine (fig 4).

2 Respiratory sinus arrhythmia RSA was smaller than in the control group in all patients, markedly so in three of them (table). It increased significantly in two and slightly in one

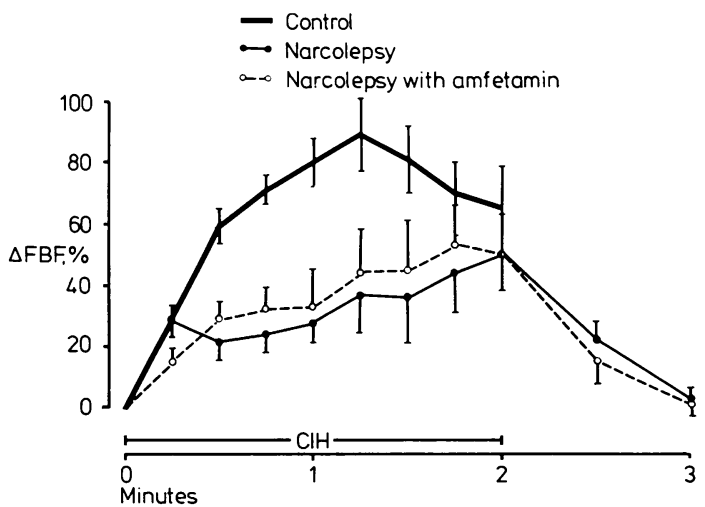

Fig 4 Change in blood flow in the resting forearm during and after contralateral isometric handgrip at 1/3 MVC for $2 \mathrm{~min}$ in the narcolepsy patients before and after amphetamine and in the control group. Mean $\pm S E$ for each category.

of the patients after amphetamine, whereas in the remaining three is was essentially unchanged. 3 Valsalva ratio The Valsalva ratio was significantly lower than in the control group in one patient, borderline low in one, normal in three and greater than in the control group in one patient, (table). Amphetamine increased the Valsalva ratio slightly in two patients but did not alter it in the remaining four. One of the patients who increased the Valsalva ratio after amphetamine also had a slight increase in RSA, the other patient unaltered RSA.

4 Effect of amphetamine in healthy subjects Amphetamine did not significantly alter RSA

Table Age and heart rate, respiratory sinus arrhythmia and Valsalva ratio before and after amphetamine in the narcolepsy patients (individual data and mean, $S D$ and $S E$ for the group) and the control group (mean and SD). Since RSA is reported to decrease with age RSA data from both an older $(a)(n=19)$ and a younger $(b)(n=5)$ control group are given.

\begin{tabular}{|c|c|c|c|c|c|c|c|}
\hline \multirow[b]{2}{*}{ Patient } & \multirow[b]{2}{*}{$\begin{array}{l}\text { Age } \\
y r\end{array}$} & \multicolumn{3}{|c|}{ Without amphetamine } & \multicolumn{3}{|c|}{ With amphetanine } \\
\hline & & $\begin{array}{l}H R \\
\text { beats/min }\end{array}$ & $\begin{array}{l}R S A \\
\text { beats/min }\end{array}$ & $\begin{array}{l}\text { Valsalva } \\
\text { ratio }\end{array}$ & $\begin{array}{l}H R \\
\text { beats/min }\end{array}$ & $\begin{array}{l}R S A \\
\text { beats/min }\end{array}$ & $\begin{array}{l}\text { Valsalva } \\
\text { ratio }\end{array}$ \\
\hline 1 & 47 & 69 & 12 & $1 \cdot 9$ & 74 & 22 & $1 \cdot 7$ \\
\hline 2 & 41 & 54 & 14 & $1 \cdot 4$ & 50 & 9 & $1 \cdot 7$ \\
\hline 3 & 52 & 48 & 3 & $1 \cdot 6$ & 57 & 12 & $2 \cdot 2$ \\
\hline 4 & 49 & 53 & 8 & $1 \cdot 3$ & 54 & 6 & $1 \cdot 3$ \\
\hline 5 & 38 & 65 & 14 & $3 \cdot 0$ & 63 & 17 & 3.6 \\
\hline 6 & 59 & 70 & 9 & $1 \cdot 5$ & 80 & 21 & $1 \cdot 5$ \\
\hline Mean & 48 & $60^{\text {n.s. }}$ & $10^{*}$ & $1 \cdot 8^{n \cdot s}$ & $63^{\text {n.s. }}$ & $15^{\mathrm{n} \cdot \mathrm{s}}$ & $2 \cdot 0^{\mathrm{n} \cdot \mathrm{s}}$ \\
\hline SD & & 9 & 4 & 0.6 & 12 & 7 & $0 \cdot 8$ \\
\hline SE & & 4 & 2 & $0 \cdot 3$ & & 3 & $0 \cdot 3$ \\
\hline \multicolumn{8}{|c|}{ Control (a) } \\
\hline Mean & 49 & 61 & 20 & $1 \cdot 9$ & & & \\
\hline SD & & 8 & 7 & $0 \cdot 3$ & & & \\
\hline $\mathrm{SE}$ & & 3 & 2 & 0.06 & & & \\
\hline \multicolumn{8}{|c|}{ Control (b) } \\
\hline Mean & 27 & 62 & 23 & & & & \\
\hline SD & & 9 & 5 & & & & \\
\hline SE & & 4 & 2 & & & & \\
\hline
\end{tabular}

For the without amphetamine data $\mathbf{n} . \mathbf{s}$. and $*$ in superscript signifies $\mathrm{p}>0.05$ and $\mathrm{p}<0.05$ respzatively for the differenze between the patient group and the older control group. For the with amphetamine data corresponding symbols refer to the effect of amphetamine. 
or the reactions to handgrip and the Valsalva mannoeuvre.

\section{Discussion}

All patients showed, when compared to the control group, smaller heart rate increase, and four out of six patients also had a smaller blood flow increase in the resting forearm on isometric handgrip. The initial blood flow increase during the first minute of contraction was reduced in all patients whereas in healthy subjects the maximal flow increase is achieved in the first minute, after which the flow tends to decline again. Experiments with closed intra-arterial injections of adrenergic blocking agents have shown that the initial flow increase is the result of $\beta$-adrenergically mediated vasodilatation while the decrease during the later phase of contraction is caused by a gradual increase in $\alpha$-adrenergic influence. ${ }^{4}$ The reason why the flow increased throughout the contraction in many patients may have been coactivation of musculature in the resting arm, which is difficult to prevent because of the high effort during the last $15-30 \mathrm{~s}$ of contraction. This was with greater certainty prevented in the volunteers in the control group since they had more time to practice before the actual experiment and, furthermore, the tendency to coactivation was checked by EMG in many of them, ${ }^{3}$ but not in the present patients. However, since coactivation would have increased blood flow and since a series of practice contractions does not alter the initial flow increase the possible lack of training in the patients would have tended to increase rather than decrease their blood flow.

In addition to the reduced heart rate and blood flow responses to muscle activation, all patients had a decreased sinus arrhythmia, although this was significant in only three out of six. Two of the six patients exhibited a moderately decreased response to the Valsalva manoeuvre. Again the possibility of smaller response in the patient due to lack of practice must be considered. Thus irregularities in breathing pattern for example because of swallowing, can affect the heart rate variations. However, respiratory flow was recorded continuously and respiratory cycles with major irregularities were discarded. Furthermore the older control group (the age range of which resembled the majority of the present patients) was not given more time to practice than the present patients.

The findings thus suggest an attenuated reactivity in the vegetative control of the cardio- vascular system in narcolepsy (at least in patients who had previously taken amphetamine). The most pronounced abnormality observed was in the reaction to the handgrip. The forearm blood flow increase on contralateral handgrip, is mediated mostly by $\beta$-adrenergic effects, ${ }^{4}$ while the heart rate increase on muscle activation mainly is the result of inhibition of vagal activity, although, at least at higher heart rates an increased sympathetic activity also plays a role..$^{11}$ The reaction to the Valsalva manoeuvre and also the sinus arrhythmia are mainly dependent on alterations in vagal activity. ${ }^{512}$ Patients with narcolepsy thus show a reduced function in mechanisms governed by both sympathetic and parasympathetic systems. Since, the sinus arrhythmia was reduced while at the same time the Valsalva reaction in most patients usually was normal, and since both these vegetative mechanisms are considered mediated by the vagus nerve, a central rather than a peripheral dysfunction seems likely. In this respect the cardiovascular reaction defects, which we have found, are similar to the previously described hippus phenomenon, which has been considered of central origin. ${ }^{13}$ These findings contrast with those in diabetic patients with known peripheral neuropathy, in whom there is a good correlation between decreased sinus arrhythmia and Valsalva ratio. ${ }^{14}$

The functional disturbance of the cardiovascular reactions studied seems not to be directly related to the severity of the disease. This may be explained by the difficulty in assessing the severity of the clinical symptoms. The lack of correlation may also be because narcolepsy includes a multitude of symptoms, possibly functionally unrelated to each other. This is supported, for example, by the fact that certain psychoactive drugs have good effects on cataplexy, sleep paralysis and hallucinations but not on sleep attacks. ${ }^{15}$

Amphetamine, which, in the patients studied, had a good effect on sleep attacks had almost no effect on the cardiovascular dysfunction. Its only recorded effect in the present study was a normalised sinus arrhythmia in two patients. The lack of effect of amphetamine on cardiovascular reflexes would be in line with the contention that amphetamine has less therapeutical effect on other symptoms of narcolepsy than the sleep attacks ${ }^{15}$ and that the sleep attacks are dissociated from the other symptoms of narcolepsy. ${ }^{16} 17$ It can be argued that the lack of effect was related to a withdrawal effect after chronic treatment. However, amphetamine had virtually no effects on the cardiovascular reflexes in the healthy volunteers and consequently it is less likely that the pre- 
ceding treatment followed by withdrawal of the drug in the patients would have affected the reaction. The findings of the present study must, however, be apparent in patients with narcolepsy who have never been treated with amphetamines.

This study was supported by Skarpö Medical Center.

\section{References}

1 Yoss RE. Treatment of narcolepsy. Modern Treatment 1969; 6:1263-74.

2 Yoss RE, Moyer NJ, Hollenhorst RW. Hippus and other spontaneous rhythmic pupillary waves. Amer J Ophthal 1970; 70:935-41.

3 Eklund B, Kaijser L, Knutsson E. Blood flow in resting (contralateral) arm and leg during isometric contraction. J Physiol 1974; 240:111-24.

4 Eklund B, Kaijser L. Effect of regional $\alpha$ - and $\beta$-adrenergic blockade on blood flow in the resting forearm during contralateral isometric handgrip. J Physiol 1976; 262:39-50.

5 Higgins CB, Vatner SF, Braunwald E. Parasympathetic control of the heart. Pharmacol Rev $1973 ; 25: 119-55$.

6 Levin AB. A simple test of cardiac function based upon the heart rate changes induced by the Valsalva manoeuvre. Amer J Cardiol 1966; 18: 90-9.

7 Graf K, Westersten A. Untersuchungen über Eigenschaften und Verwendungsmöglichkeiten eines flexiblen Extremitätenplethysmografen. Acta Physiol Scand 1959; 46:1-18.

8 Freyschuss U, Melcher A. Sinus arrhythmia in man: Influence of tidal volume and oesophageal pressure. Scand J Clin Lab Invest 1975; 35: 487-96.

9 Berglund B, Wajngot A, Freyschuss U, Efendic S. Cardiovascular reflexes in diabetics without clinical signs of autonomic neuropathy. Scand J Clin Lab Invest 1980; 40:284-91.

10 Macdonald HR, Sapru RP, Taylor SH, Donald $\mathrm{KW}$. The effects of intravenous propranolol (Inderal) on the systemic circulatory response to sustained handgrip. Amer J Cardiol 1966; 18: 333-43.

11 Freyschuss U. Cardiovascular adjustment of somatomotor activation. Acta Physiol Scand 1970; Suppl. 342:1-32.

12 Wheeler T, Watkins PJ. Cardiac denervation in diabetes. Brit Med J 1973; 4:584-6.

13 Duke-Elder S, Scott G. Periodic phenomena. In: Duke-Elder S, ed. System of ophthalmology. London: Henry Kimpton, 1971: Vol 11, 637-9.

14 Baldwa VS, Ewing DJ. Heart rate response to Valsalva manoeuvre. Reproducibility in normals, and relation to variation in resting heart rate in diabetics. Brit Heart J 1977; 39:641-4.

15 Takahashi $\mathrm{S}$. The action of tricyclics (alone or in combination with methylphenidate) upon several symptoms of narcolepsy. In: Guilleminault C, Dement WC, Passouant P, eds. Narcolepsy. New York: Spectrum Publ Inc, 1976: Vol. 3, 625.

16 Rechtschaffen A, Wolpert E, Dement W, Mitchell S, Fisher C. Nocturnal sleep of narcoleptics. Electroencephalograph Clin Neurophysiol 1963; 15:599-609.

17 Suzuki J. Narcoleptic syndrome and paradoxical sleep. Folia Psychiatr Neurol Japon 1966; 20: $123-49$. 